\title{
Emergência Conjunta dos Comportamentos de Ler e Escrever Palavras e Identificar Números após o Ensino em Separado desses Repertórios
}

Joint emergency of the behaviors of reading and write words and identifying numbers after the separate teaching

José Gonçalves Medeiros, Aline

Vettorazi, Amanda

Kliemann, Layla

Kurban \& Maria

Salete Mateus

Universidade Federal

de Santa Catarina

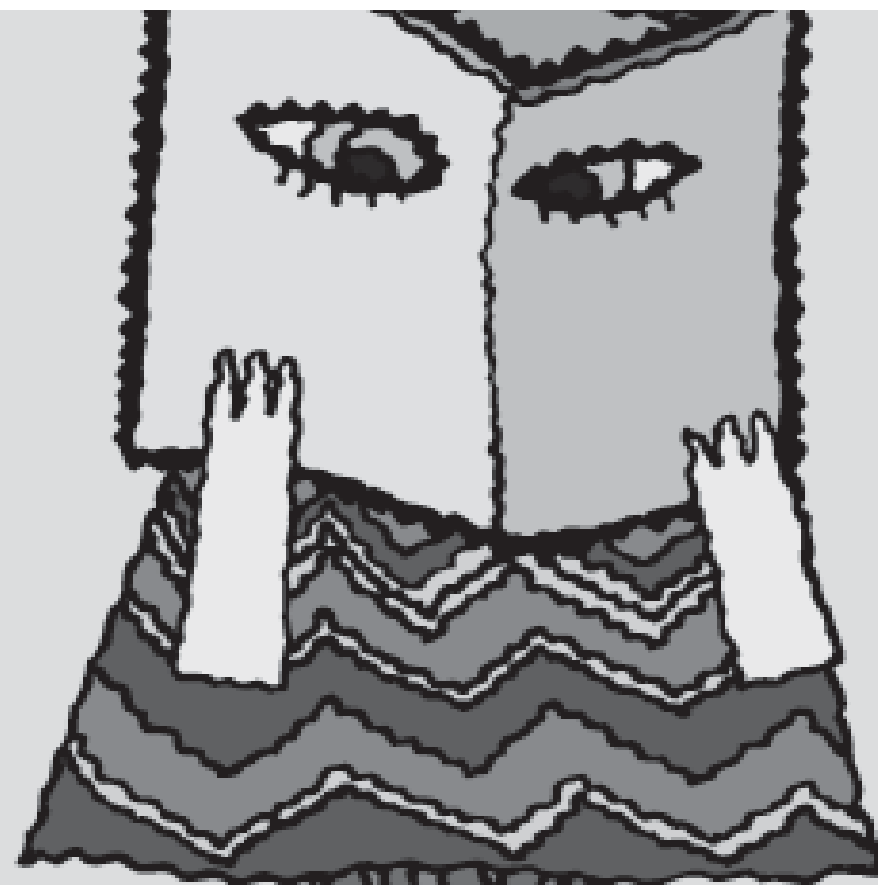

O autor (José Gonçalves Medeiros) agradece ao CNPq pelo apoio financeiro, recebido através de Bolsa de Produtividade em Pesquisa e Edital Universal. Agradece também a direção do Colégio Estadual Simão José Hess, de Florianópolis, que acolheu e tem acolhido nosso grupo de pesquisa em suas dependências para a coleta de dados 


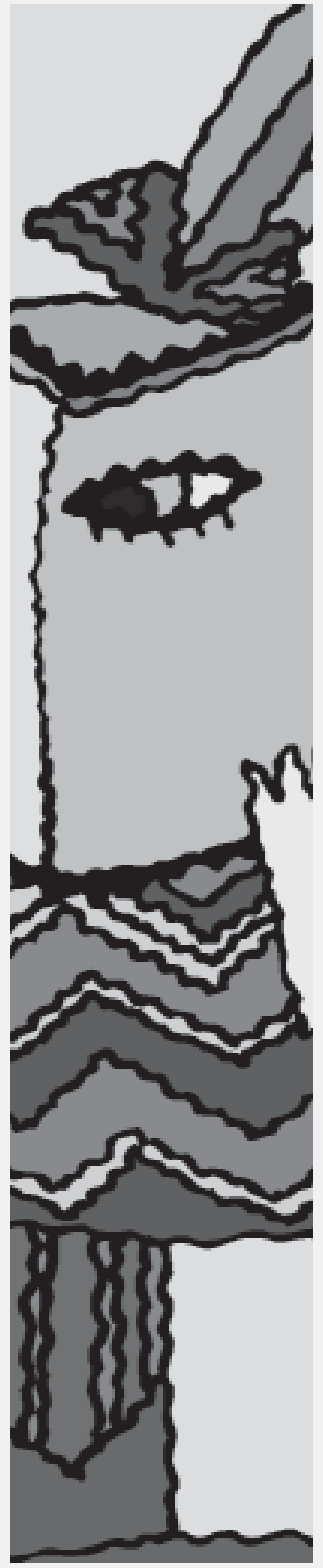

Resumo: Doze crianças, do sexo masculino e feminino, da primeira série do ensino fundamental público e que não apresentavam o repertório de ler e o de identificar números foram os participantes. Suas idades variavam entre 6 e 8 anos. Os comportamentos foram ensinados por meio de um procedimento de discriminação condicional. Verificou-se a ocorrência da aprendizagem sem erro das relações ensinadas para todos os Ps, exceto para um (P10). Nas etapas de testes das relações BC/CB, os Ps estabeleceram as equivalências. No teste das relações C'D, os Ps leram as novas expressões, agora compostas por palavras e números, além de outras expressões de generalização. Os dados são discutidos, mostrando que o ler e escrever palavras e identificar números são classes de estímulos equivalentes e que o ensino delas facilitou e promoveu a leitura com compreensão, tornando-se possível a extensão do procedimento para uma situação aplicada.

Palavras-chave: Ler; Identificar números; Equivalência palavra-número; Dificuldades de aprendizagem.

Abstract: The subjects have been twelve children of both sexes, belonging to a class of the elementary course in its first year in a public school. Such children did not exhibit the repertoires of reading or of identifying numerals. Their ages shifted between 6 and 8 years. Such behaviors have been taught by means of a conditional discriminative procedure. The occurrence of learning without error of the taught relations for all Ps has been found out, except from one of them (P10). During test steps of relations BC/ $\mathrm{CB}$, the Ps established equivalencies. During the test of relations C'D, the Ps read new terms, now composed of new words and numerals, in addition to other generalizing terms. The related data are discussed, showing that reading and writing words and identifying numerals are classes of equivalent stimuli, and that teaching them facilitated and improved reading with understanding, making possible the extension of such a procedure to an applied situation.

Keywords: reading, identifying numerals; word-numeral equivalency; difficulties in learning.
Os estudos de equivalência de estímulos têm demonstrado que palavras ditadas, palavras impressas e suas respectivas figuras podem se tornar equivalentes após um procedimento de ensino de, pelo menos, duas dessas relações (A-B / A-C). A mesma afirmativa pode ser feita em relação ao ensino de números e seus respectivos nomes. Ou seja, tanto classes de palavras quanto classes de números, ambas consideradas como classes de comportamento verbal, podem ficar sob controle de estímulos condicionais, o que nos possibilitaria verificar se os elementos dessas classes se tornariam equivalentes entre si, possibilitando aos educadores ensinar essas classes em qualquer ordem. Cairia por terra, portanto, a noção de 
que linguagem é um pré-requisito para o ensino de numerais, conceito de número, operações aritméticas, etc. Desse modo, o presente artigo pretende responder à seguinte pergunta de pesquisa: "que tipo de relações emergem quando o ler e escrever palavras e o identificar número são ensinados independentemente e, numa situação de teste, são apresentados juntos?”. Desse modo, a presente pesquisa enfocou primeiramente a aquisição do ler e escrever e, na seqüência, o de identificar números (Monteiro e Medeiros, 2002), fundamentado nos estudos de equivalência de estímulos (Sidman, 1971; Sidman \& Tailby, 1982; Dixon, 1977; de Rose, 1993; Souza \& de Rose, 1997; Barros, 1996; Hübner, 1997).

O emparelhamento de figuras com palavras constitui um marco histórico no processo de desenvolvimento dos estudos de equivalência. O trabalho de 1971, realizado por Sidman, deu início a uma série de investigações em

1 No diagrama do estudo de Sidman de 1971 (ver Figura 1), realizado com adolescentes com deficiência mental, a seta contínua grossa (BD) representa relações de pareamento que os sujeitos já dominavam antes do início do experimento, ou seja, eram capazes de nomear as figuras que lhes foram apresentadas. As setas contínuas finas representam relações que lhes foram ensinadas: a seta $A B$ indica que foram capazes de, frente a palavras ditadas, escolherem as figuras correspondentes e a seta $A C$ indica que foram capazes de selecionar uma palavra impressa frente a uma palavra ditada. As setas tracejadas indicam que em decorrência do ensino, os adolescentes foram capazes de emparelhar palavras impressas com suas respectivas figuras $(C B)$ e a emparelhar figuras com seus respectivos nomes (BC) e a ler oralmente $(C D)$. aquisição de leitura e escrita, inaugurando, assim, uma nova área de pesquisa (Sidman \& Cresson, 1973; d’Oliveira, 1990; Melchiori, Sousa \& de Rose, 1992; d'Oliveira \& Matos, 1993; Aiello, 1995; Matos, Hübner \& Peres, 1997; Antonakopoulu, Amorim, Medeiros \& Righetto, 1997a; Medeiros, Monteiro \& Silva, 1997b). Os resultados obtidos por Sidman sugerem que se uma pessoa aprende, por meio dessa forma de discriminação, as relações ${ }^{1}$ entre palavra falada e figura (AB), entre palavra falada e palavra impressa (AC), as relações CB (entre palavra impressa e figura), BC (entre figura e palavra impressa) e CD (entre palavra impressa e sua respectiva leitura pelo sujeito) podem emergir sem que elas tenham sido diretamente ensinadas, como pode ser visto na Figura 1. Nesse sentido, o paradigma de equivalência de estímulos tem sido frequentemente utilizado, na medida em que oferece bases para uma análise experimental de comportamentos emergentes (Mackay, 1985; Sidman, 1990).

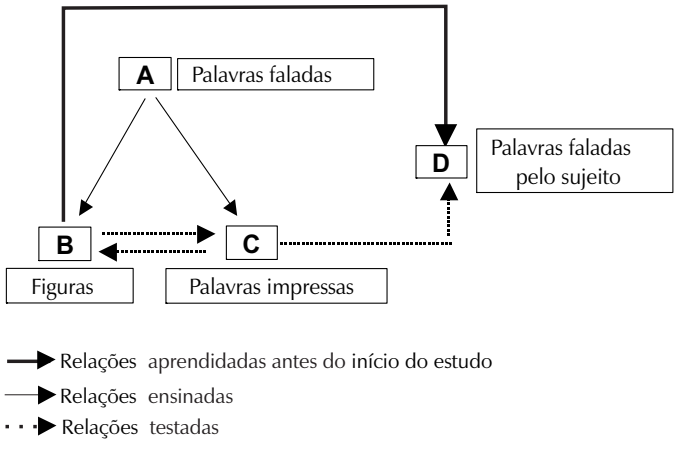

Figura 1. Diagrama das primeiras relações ensinadas por Sidman (1971).

Na literatura sobre o ensino de ler e escrever, há uma ampla variedade de procedimentos de como ensinar estes repertórios, bem como o de ensinar os comportamentos matemáticos de conceituar (contar, identificar números, etc.), porém em menor quantidade em números de artigos. Uma análise desses procedimentos mostra que os estímulos utilizados possuem elementos comuns. Dessa forma, estímulos numéricos usados (1, 2, 3,4 , 5, etc.) em estudos de equivalência podem ser classificados como um conjunto de figuras (estímulos do conjunto B) relacionado ao conjunto das palavras relacionadas a seus nomes (um, dois, três, quatro, cinco, etc.- conjunto C). Desse modo, o ensino de um elemento da categoria (“um”, por exemplo) e o ensino de um elemento de outra categoria (“1”, por exemplo) deveria garantir, segundo a literatura da área, a equivalência entre "um” e "1", assim como a reversibilidade, ou seja, "1" e "um". Assim, tendo sido ensinados a leitura de palavras ("bola", por exemplo), separadamente do ensino de números (3, três, etc.), o que ocorreria se apresentássemos juntos palavra e número, em situação de teste? O sujeito leria, sem ter-lhe sido apresentado antes, essa nova configuração de estímulos? Ou seja, ele leria "1 bola", "três bolas", entre outras combinações? Este procedimento, além de econômico em termos de tempo, poderia estar garantindo uma integração maior entre conteúdos ensinados separadamente para as crianças que iniciam a educação de primeiro grau. 
O trabalho apresentado está relacionado teórico e metodologicamente àqueles que foram realizados nos últimos quinze anos, em que Medeiros, Konescki e Souza (1993) e Medeiros, Teixeira, Cabral, Silva e Brandão (1996) trabalharam com crianças com história de fracasso escolar em um programa de ensino de discriminações condicionais, onde os modelos eram palavras faladas e os estímulos de comparação eram palavras impressas (compostas por duas e por três sílabas). Os resultados obtidos com estes projetos mostram um aumento significativo do número de palavras que as crianças passaram a ler em relação ao repertório de entrada, além da emergência de novas relações que surgiram a partir das relações condicionais ensinadas. Ao excluir a palavra conhecida e escolher a nova diminui-se a probabilidade de insucesso na aquisição de novas palavras. Daí a denominação de aprendizagem sem erro. Para uma criança com história de fracasso ocasionada, em parte, por seus insucessos no processo de aquisição do repertório textual, um procedimento desta natureza deveria motivá-la (os estudos da área têm demonstrado) a prosseguir na tarefa escolar o que possivelmente refletirá nas atividades da sala de aula.

Com base no referencial teórico sobre equivalência de estímulos, foi desenvolvido e sistematizado um procedimento para se trabalhar com crianças que apresentavam porcentagens baixas de leitura de palavras e números de uma escola da rede pública. Esse estudo, portanto, avaliou o resultado da apresentação conjunta dos estímulos palavras e números, ensinados separadamente, por meio de um procedimento de equivalência de estímulos computadorizado.

\section{Método}

\section{Participantes}

Participaram desse procedimento 12 crianças (4 do sexo masculino e 8 do feminino), doravante denominados participantes (Ps), cujo repertório de leitura e escrita de palavras, bem como o de identificar números era percentualmente baixo. As idades variavam entre 6 e 8 anos, sendo que todos os eles eram alunos da $1^{\text {a }}$ série do Ensino Fundamental, provenientes de duas turmas com professoras diferentes, de uma escola da rede pública de Florianópolis (SC).

\section{Seleção dos Ps}

Os Ps foram selecionados a partir dos resultados de um teste de leitura de palavras e de identificação de números em aplicações individuais, bem como através da indicação da professora das crianças que manifestavam um repertorio reduzido de comportamentos de ler, escrever e identificar números. Dois critérios foram utilizados para escolher os Ps: crianças que não fizeram o curso pré-primário e que apresentaram baixas porcentagens de acerto (na faixa de 0 a 20 por cento) nos testes de leitura e de identificação de números.

\section{Local}

O procedimento experimental foi realizado no Laboratório de Informática da Escola, instalado numa das salas de aula do andar térreo do prédio. A sala possui 7,5 metros de largura por 9 de comprimento, com duas janelas grandes ocupando toda parede lateral oposta à porta. Contém ainda, um aparelho de ar condicionado, 14 computadores, sendo 3 utilizados para a pesquisa, e 8 lâmpadas. É uma sala ampla, bem iluminada e bem arejada.

\section{Material e equipamento}

Foram utilizados três computadores, com recurso multimídia, placa de som, alto-falantes Labtec LCS 150, CD-ROM, impressora e o software Mestre@ (Goyos e Almeida, 1996). Fones de ouvido também foram utilizados para evitar a interferência dos estímulos auditivos provenientes do ambiente. 


\section{Procedimento}

O principal procedimento utilizado foi o de exclusão, usado para expandir gradualmente, ao longo de uma seqüência de passos, o repertório de pareamentos entre modelos e estímulos de comparação. A base do procedimento de exclusão consiste na presença, em cada tentativa de pareamento, de um estímulo de comparação conhecido pelo participante, que é apresentado juntamente com outro estímulo de comparação desconhecido. Quando o experimentador apresenta o estímulo modelo correspondente ao estímulo de comparação desconhecido, o estímulo de comparação conhecido funciona como pista ou deixa para que o participante o rejeite e selecione corretamente o estímulo de comparação desconhecido.

Neste programa, o procedimento de exclusão era constituído de relações $\mathrm{AB}$ (estímulo auditivo-figura), BC (figura-palavra impressa), AC (estímulo auditivo-palavra impressa), AF (estímulo auditivo-anagrama) e CF (palavra impressa-anagrama), ensinadas nas etapas de exclusão ou ensino (conforme Etapa 2/Passo 2 explicitado abaixo). Vale ressaltar que o ensino do comportamento de ler e escrever palavras ocorreu de maneira independente do ensino do comportamento de identificar números. As respectivas exclusões foram apresentadas de forma intercalada para cada criança; dessa maneira, em uma sessão eram ensinadas palavras (denominadas exclusões de português) e na outra, números (denominadas de exclusões de matemática).

Tabela 1. Exemplos de palavras e números ensinados separadamente e testados conjuntamente.

\begin{tabular}{|l|l|}
\hline Ensino de palavras & $\begin{array}{l}\text { Bola, mago, tatu } \\
\text { Ensino de números }\end{array}$ \\
$\begin{array}{l}\text { 1, 2, 3, um, } \\
\text { dois, três }\end{array}$ \\
\hline Teste de emergência & $\begin{array}{l}\text { 1 bola, um mago, } \\
\text { uma bola, três tatu, } \\
\text { dois magos, etc. }\end{array}$ \\
\hline
\end{tabular}

O procedimento consistiu, portanto, das etapas de pré-testes (conforme Etapa2/Passo1 explicitado abaixo) em que se verificavam respectivamente a aquisição de leitura das palavras e números ensinados na exclusão anterior (denominadas palavras e números de linha de base), a leitura de números e palavras novas a serem ensinadas por meio do procedimento de exclusão (referidas como palavras e números de ensino), bem como de palavras novas não diretamente ensinadas (referidas como palavras de generalização), formadas a partir das sílabas das palavras de ensino da Linha de Base imediatamente anterior.

As palavras de ensino eram dissílabas e as palavras de generalização foram obtidas por recombinação das mesmas sílabas. O pós-teste avaliou as palavras ensinadas (rAC) na exclusão e as palavras de generalização (rA’C).

\section{Fase A: linha de base, exclusão, montagem e pós-teste.}

\section{Etapa 1- Linha de base}

A Linha de Base foi realizada com a finalidade de verificar o repertório inicial da criança, e foi composto dos passos descritos a seguir:

\section{Passo 1: Pré-teste}

No pré-teste foram apresentadas, uma de cada vez, sem qualquer conseqüência experimental planejada, três figuras e respectivas palavras relativas ao procedimento de ensino de português e três figuras e respectivos números relativos ao procedimento de ensino de matemática. Após a apresentação destas figuras, palavras e números, prosseguiu-se para o passo de ensino de cada uma das relações.

\section{Passo 2: Ensino (ou exclusão)}

$\mathrm{Na}$ configuração da apresentação dos estímulos, um quadrado branco aparecia na parte superior da tela do computador (PC), acompanhado do estímulo modelo (auditivo) correspondente a uma das relações que estava 
sendo ensinada. O clicar sobre o quadrado branco produzia, na parte inferior da tela, o aparecimento do estímulo de comparação (podendo ser uma palavra, uma figura ou um número) correspondente ao estímulo modeloauditivo. O clicar sobre o estímulo de comparação correto produzia conseqüências, na forma de imagens, em toda a tela de cenas de crianças brincando acompanhada de uma das expressões verbais como "perfeito" ou "muito bem” ou "é isso aí, meu” ou "excelente" (Nessas cenas, os personagens da tela realizavam as brincadeiras de forma correta). Se o clicar fosse sobre o estímulo de comparação incorreto, as expressões verbais podiam ser: “Ah! Você errou!” ou "que dó, você errou!” ou “oh! oh! você errou!” (Nessas cenas, os personagens da tela realizavam as brincadeiras de forma incorreta). Essas conseqüências eram liberadas de forma aleatória pelo próprio programa de ensino e consistiam na apresentação, após cada tentativa, da figura de uma criança jogando basquete, pulando corda, brincando de patins e brincando de skate.

\section{Passo 3: Montagem}

Tentativas de montagem foram também realizadas. O programa apresentava palavras (cópia) na parte superior da tela do computador. O clicar sobre a palavra produzia o aparecimento, na parte inferior da tela do PC, de letras relativas à palavra em ordem não seqüencial. O clicar sobre as letras da seqüência correta produzia, na parte superior da tela do PC, logo abaixo da palavra modelo, a formação, letra por letra, da palavra. Montagens corretas ou incorretas produziam as conseqüências, semelhantemente às descritas no Passo 2.

\section{Passo 4: Pós-teste:}

Idêntico ao Passo 1, exceto que eram apresentadas apenas as três palavras de ensino.

\section{Etapa 2 - Exclusão}

\section{Passo 1: Pré-teste}

Idêntico ao Passo 1 da Etapa 1, exceto que eram acrescentadas mais três palavras e três números (as palavras e os números ensinados na Linha de Base e as palavras de generalização).

\section{Passo 2: Ensino (ou exclusão)}

Semelhante ao Passo 2 da Etapa 1 descrita logo acima.

\section{Passo 3: Montagem}

Semelhante ao Passo 3 da Etapa 1 descrita logo acima.

\section{Passo 4: Pós-teste}

Semelhante ao Passo 4 descrita logo acima, com o acréscimo de três palavras de generalização.

\section{Fase B: Equivalência}

Etapa 3: Ensino de identificação das figuras. Antes de dar início à fase de equivalência apresentou-se, na parte inferior da tela, na forma impressa, as figuras correspondentes às palavras de ensino, uma de cada vez, com o estímulo modelo apresentado de forma auditiva. Os Ps foram instruídos a escolher uma das figuras. Caso a resposta do P fosse correta ou incorreta, ela era consequenciada de acordo com o descrito na Passo 2 da Etapa 1.

\section{Passo 1: Figura como estímulo-modelo}

Nesta etapa do procedimento, a figura impressa funcionava como estímulo-modelo e os nomes das figuras como estímulos de comparação (rBC: relação figura-palavra impressa), sendo correto aquele que correspondia ao estímulo-modelo o estímulo correto. Inicialmente aparecia uma figura na parte superior da tela. O clicar do mouse sobre ela produzia o aparecimento de três palavras impressas na parte inferior da tela. O sujeito deveria escolher a palavra impressa correspondente à figura que se encontrava na parte superior, sem qualquer conseqüência experimentalmente planejada para as escolhas corretas ou incorretas.

Passo 2: Nome da figura como estímulo - modelo Nesse passo, o nome de uma das figuras (palavra impressa) funcionava como modelo 
e as figuras como estímulos de comparação (rCB: relação palavra impressa- figura), sendo um deles, o correto. Com exceção da mudança de posição dos estímulos modelos e de comparação, o restante do procedimento ocorria como descrito no Passo 1.

\section{Fase C: Teste de emergência de novas relações}

Nesta fase os números e as palavras ensinadas nas Etapas 1 e 2 foram testados conjuntamente, conforme apresentado na Tabela 2.

Tabela 2. Ordem de apresentação dos procedimentos de ensino e de testes.

\begin{tabular}{|c|l|c|l|}
\hline Ordem & \multicolumn{1}{|c}{ Procedimento } & Ordem & \multicolumn{2}{c}{ Procedimento } \\
\hline 1 & Linha de base & 9 & Testes de equivalência de Português e Matemática 2 \\
\hline 2 & Exclusão de Matemática 1 & 10 & Teste de agrupamento 2 \\
\hline 3 & Exclusão de Português 1 & 11 & Exclusão de Português 4 \\
\hline 4 & Testes de equivalência de & 12 & Exclusão de Matemática 3 \\
\hline 5 & Português e Matemática & & \\
\hline 6 & Teste de agrupamento 1 & 13 & Exclusão de Português 5 \\
\hline 7 & Exclusão de Português 2 & 14 & Testes de equivalência de Português e Matemática \\
\hline 8 & Exclusão de Matemática 2 & 15 & Teste de agrupamento 3 \\
\hline
\end{tabular}

Os testes da Fase C verificaram a emergência conjunta dos comportamentos de ler e escrever e de identificar números, ensinados em exclusões separadas como descrito anteriormente.

O programa prosseguiu alternando passos de exclusão (numerados seqüencialmente) com passos de equivalência (também numerados seqüencialmente) e testes de agrupamento. Contudo, a criança passava de uma fase para a outra, somente quando atingia os critérios abaixo descritos:

- Pré-Teste: $100 \%$ de acerto, em uma sessão, da leitura das palavras da Linha de Base. Se o participante não respondesse neste nível de acerto, o experimentador apresentava a Exclusão imediatamente anterior.

- Exclusão: 91,6\% de acerto, em uma sessão, na montagem das relações AF (estímulo auditivomontagem) e a montagem nas relações CF (palavra impressa-montagem); 95,2\% na identificação das relações AB (estímulo auditivo-figura), das relações AC (estímulo auditivo-palavra impressa) e relações BC (estímulo figura-palavra impressa).

- Pós-Teste: $100 \%$ de acerto em uma sessão na relação AC das palavras de ensino.

Não foram estabelecidos critérios para o teste de equivalência, bastando apenas a realização do mesmo. Já para os testes de agrupamento, a criança passava para o passo seguinte apenas com $100 \%$ de acertos.

\section{Resultados e discussão}

Nesta seção, estão descritas as porcentagens de acertos apresentadas pelos Ps nas etapas de ensino de leitura e escrita das palavras selecionadas, da identificação de números (rAC), bem como as porcentagens verificadas no agrupamento de palavras e números (rCD). 
Os resultados estão descritos em grupos de quatro Ps de modo a facilitar a comparação e a visualização das porcentagens obtidas. Dessa forma, a Figura 2 apresenta a porcentagem de acertos nas relações AC ao longo do procedimento de exclusão de português e matemática dos Ps 1, 2, 3 e 4. Apresenta ainda, a porcentagem de acertos da relação CD do teste de agrupamento dos mesmos Ps.

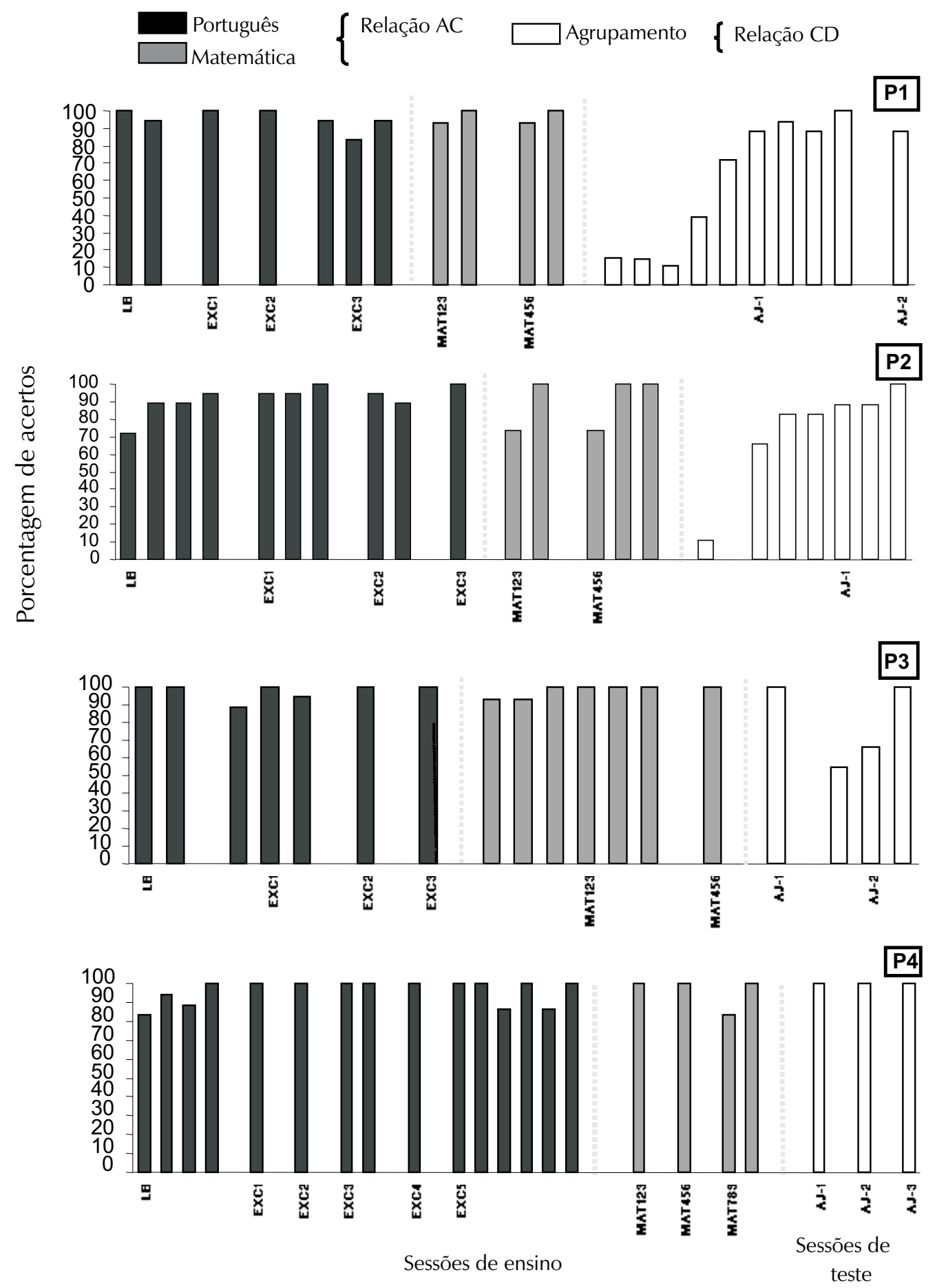

Figura 2. Porcentagem de acertos das relações AC das exclusões de Português e Matemática e das relações $\mathrm{CD}$ do teste de agrupamento dos Ps 1, 2, 3 e 4. 
Verifica-se que P1, P3 e P4 obtém porcentagem de acerto acima de 80 por cento em todas as relações AC das exclusões de Português e Matemática realizadas (11, 14 e 19 sessões respectivamente). Já P2 apresenta um rendimento em torno de 70 por cento em três das quinze sessões realizadas (uma em Português e duas em Matemática).

Em relação ao teste de agrupamento 1 (AJ-1), pode se verificar que todos os quatro Ps mostram, ao final, 100 por cento de acertos, contudo, como é possível observar na Figura 1, P1 e P2 apresentam um aumento gradual e progressivo da porcentagem de acertos ao longo de nove sessões para P1 e oito para P2. E na única sessão realizada, P3 e P4 obtém 100 por cento de acertos. No segundo teste de agrupamento (AJ-2), P1 obtém 88 por cento de acertos com apenas uma sessão; P2 não atingiu essa etapa; P3, em AJ-1, obtém 100 por cento de acertos e, em AJ-2, os dados mostram um aumento gradual e progressivo da porcentagem de acertos nas três sessões realizadas ao longo do procedimento; P4 obtém 100 por cento de acertos nos três testes de agrupamento realizados.

A Figura 3 apresenta a porcentagem de acertos dos Ps 5, 6, 7 e 8. Verifica-se que P7 obtém porcentagem de acertos acima de 80 por cento em todas as 21 exclusões da relação AC de Português e Matemática. Já P5 e P8 apresentam rendimento superior a 80 por cento em 16 das 19 e 20 sessões respectivamente realizadas; P6 obtém porcentagem semelhante em 18 das 20 sessões realizadas.

No teste de agrupamento 1 (AJ-1) os Ps 5 e 6 apresentam um aumento gradual e progressivo da porcentagem de acertos ao longo das nove sessões. P7 e P8, por sua vez, ficaram de imediato sob controle de estímulos do teste com acertos entre 80 e 100\% em todas as sessões dos agrupamentos (AJ-1 e AJ-2). 
$\square$ Português
Matemática $\{$ Relação AC $\square$ Agrupamento $\{$ Relação CD

P5

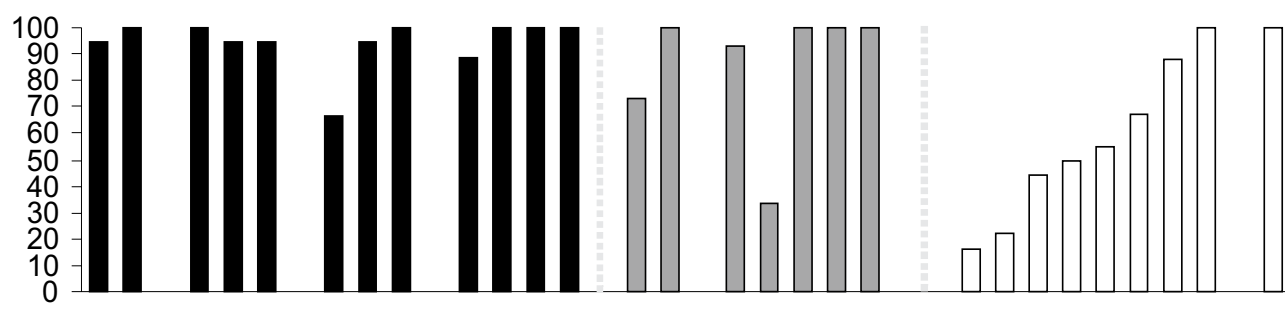

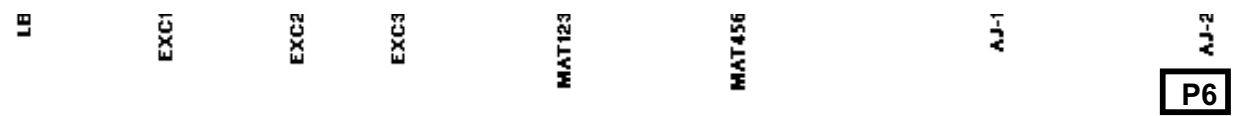
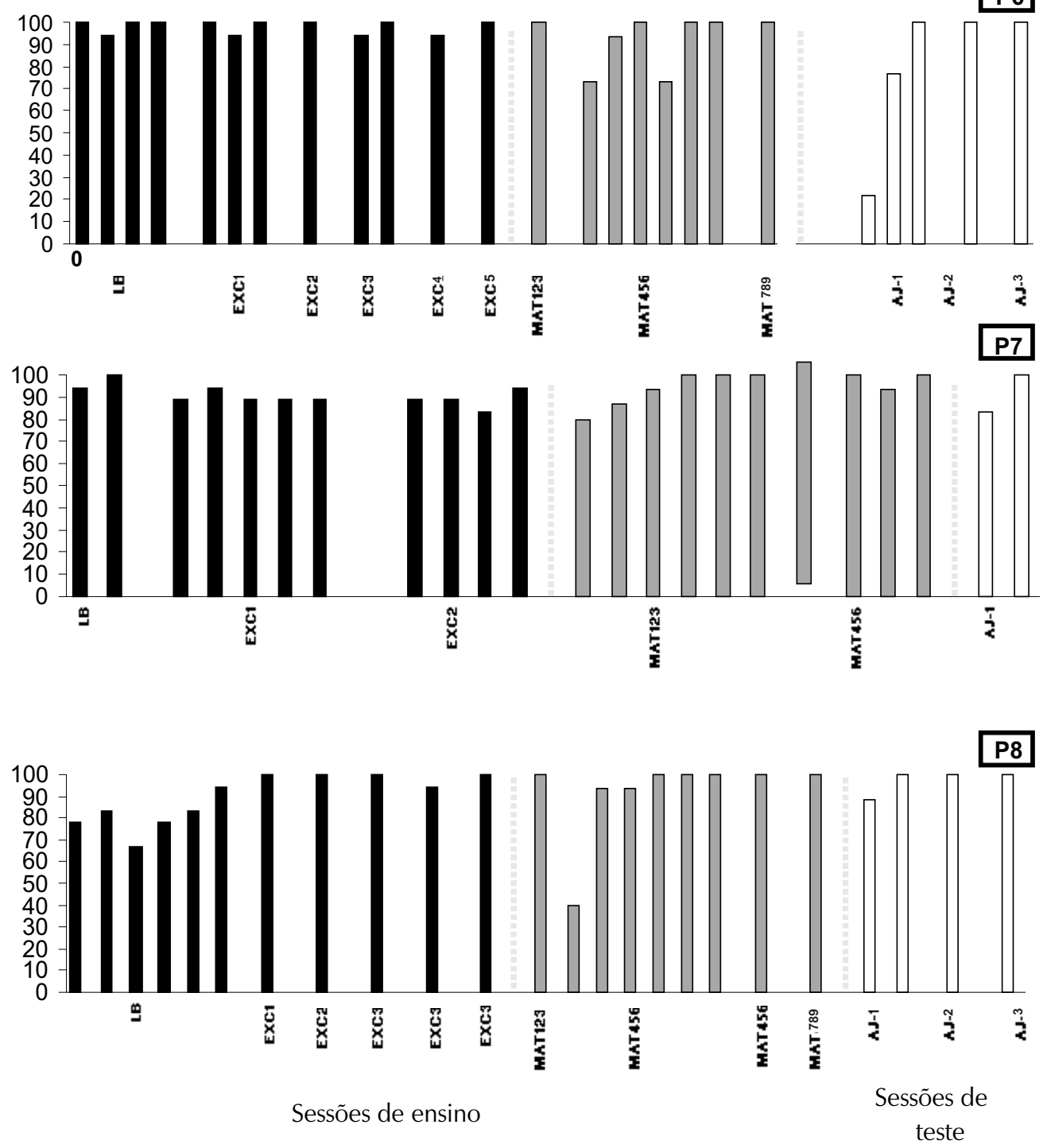

Figura 3. Porcentagem de acertos das relações AC das exclusões de Português e Matemática e das relações $\mathrm{CD}$ do teste de agrupamento dos participantes 5, 6, 7 e 8 . 
Por fim, como pode ser visto na Figura 4, observa-se que, na relação AC das exclusões de Português e Matemática realizadas, P9 obtém porcentagem de acertos acima de 80por cento em 17 das 19 sessões realizadas. P11 e P12 apresentam 16 sessões com rendimento acima de 80 por cento, sendo que o primeiro realizou 24 sessões enquanto o segundo realizou 20.

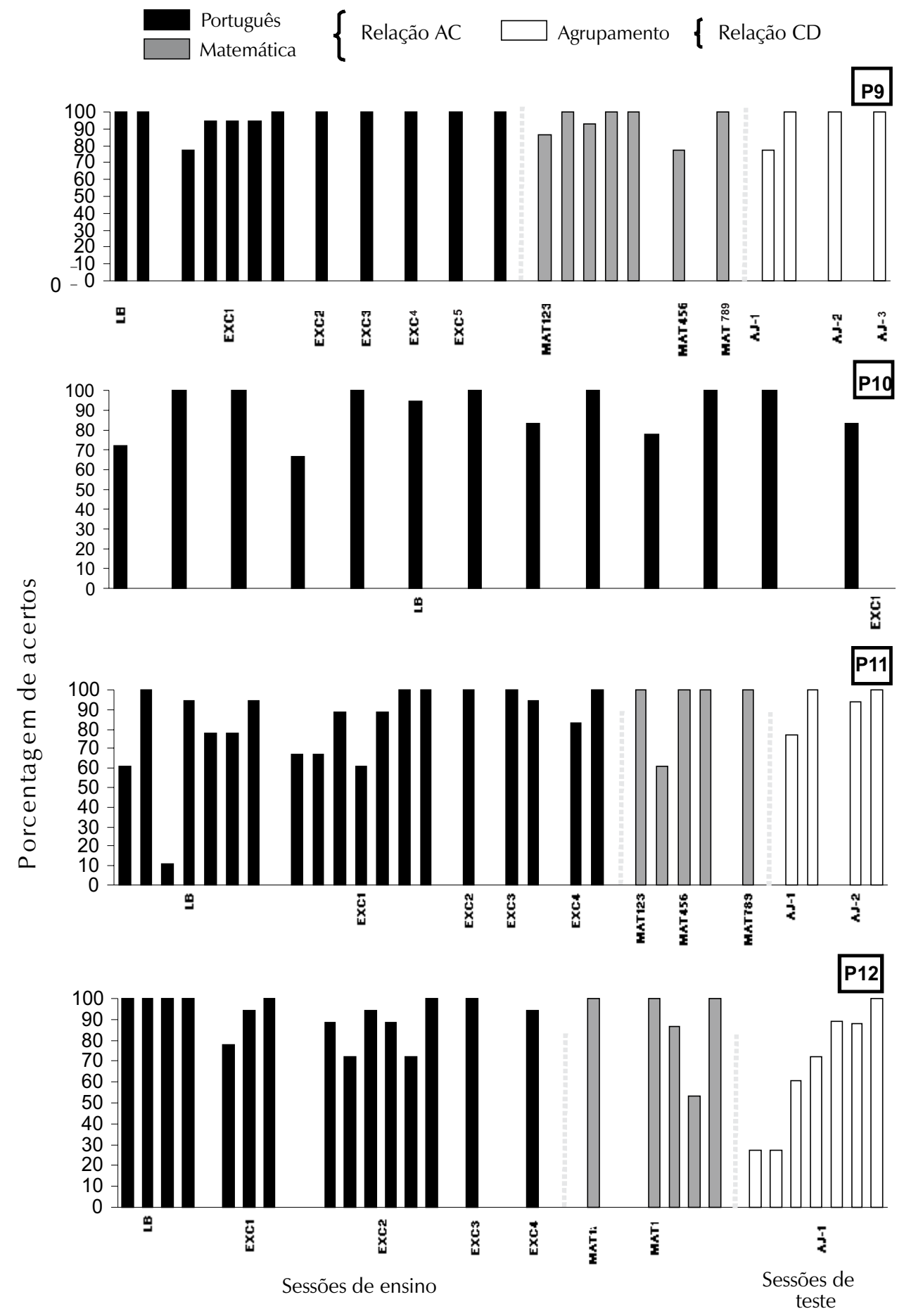

Figura 4. Porcentagem de acertos das relações AC das exclusões de Português e Matemática e das relações $\mathrm{CD}$ do teste de agrupamento dos participantes 9, 10, 11 e 12. 
Todos os Ps apresentam desempenho semelhante nas exclusões AC, tanto de português como de matemática, obtendo, em sua maioria, um rendimento acima de $80 \%$ de acertos (189 tentativas no total de 218). No entanto, P10 obtém rendimento discrepante em relação aos demais, uma vez que permaneceu ao longo de todo procedimento apenas nas etapas de Linha de Base e Exclusão 1 de Português e Matemática. A exclusão de Matemática foi realizada em duas sessões, contudo, o participante não finalizou o procedimento e, por conseguinte, os dados não foram computados. Esse participante apresenta porcentagem de acertos acima de 80 por cento em 10 das 13 tentativas AC de português.

Uma possibilidade de explicação para tal rendimento pode estar relacionada ao fato de que P10, por não ficar sob o controle de estímulos programado, apresentava-se “inquieto” ao longo do procedimento, movimentando-se na cadeira e dispersandose com freqüência com outros estímulos que não fossem os do procedimento, como barulho na rua, objetos em cima da mesa, botões do computador, entre outros. Para que o rendimento da criança não fosse prejudicado, na metade do ano letivo programou-se um procedimento especial com ele, no qual o experimentador, durante as sessões de exclusão, posicionava-se ao seu lado. auxiliando-a no manuseio do mouse e selecionando as alternativas apontadas na tela pela criança, além de substituir o estímulo auditivo eletrônico (do fone de ouvido) pela própria voz do experimentador. Ademais, o experimentador reforçava as tentativas corretas da criança referentes ao procedimento, bem como não consequenciava comportamentos dispersivos por ocasião de suas ocorrências.

Contudo, apesar do procedimento especial ter sido introduzido, o rendimento do participante (P10) não sofreu as alterações esperadas. Em reunião com a professora, descobriu-se que a criança havia sido encaminhada para atendimento psiquiátrico e que foi diagnosticada com Transtorno de Déficit de Atenção por Hiperatividade (TDAH), passando então, a ser medicada com ritalina nos últimos meses letivos (novembro e dezembro de 2004). Nesse período, a criança passou da Linha de Base 1 para a Exclusão 1.

Nas sessões do agrupamento AJ-1, os Ps 9 e 11 apresentam porcentagens de acerto em torno de 80 e, em AJ-2 e AJ-3, ambos os Ps apresentam porcentagens de acerto próximas de 100 por cento. Os dados de P12, por sua vez, mostram uma aquisição gradual dos repertórios de leitura das novas expressões (números + palavras).

Ao comparar o número de tentativas realizadas em cada teste de agrupamento, visualizados nas Figuras 2, 3 e 4, percebe-se que para oito Ps $(1,2,5,6,7,8,9$ e 12) houve um maior número de sessões realizadas no primeiro teste, sendo que a partir do segundo teste, cinco Ps (1, 5, 6, 8 e 9) atingem 100 por cento de acertos em uma única sessão realizada. P1, P7 e P12 realizaram somente o primeiro teste de agrupamento, uma vez que cada criança desempenhava as atividades em seus ritmos individuais, repetindo-as quantas vezes fosse necessário até que os critérios mínimos para a nova etapa fossem atingidos.

Inversamente a esse padrão de desempenho, P3 obteve $100 \%$ de acertos na primeira sessão do teste de agrupamento 1 e realizou um número maior de sessões (três) no segundo teste. Já, para P4 e P11, o número de sessões realizadas foi aproximadamente igual. P4 realizou uma sessão para cada um dos três testes e P11 realizou duas sessões tanto para o primeiro como para o segundo. P10 foi a exceção, por não ter realizado nenhum teste de agrupamento.

Os Ps foram também capazes de emparelhar palavras impressas com suas respectivas figuras (CB) e a emparelhar figuras com seus
Para que o rendimento da criança não fosse prejudicado, na metade do ano letivo programouse um procedimento especial com ele, no qual o experimentador, durante as sessões de exclusão, posicionava-se ao seu lado. 
respectivos nomes (BC) e lê-las oralmente (CD). Esses dados podem ser visualizados na Figura 5, na qual se verifica que praticamente todos os Ps apresentaram altas porcentagens de acertos, com valores próximos de 100 por cento. As exceções foram os Ps 1 , 2 e 12 nas equivalências de matemática. Para os Ps 1 e 2 as porcentagens de acerto ficam em torno de 70 a 80 por cento e para P12, o percentual de acertos permanece em torno de 30 por cento em M1 e 0 por cento em M2. Observa-se, ainda, que de 53 tentativas realizadas no total, por todos os Ps, tanto nas equivalências de português quanto de matemática, apenas em cinco tentativas, o percentual de acertos fica abaixo de 80 por cento (P1 e P11 obtém 66 por cento na EQ2 de matemática, P2 obtém 66 por cento na EQ1 de matemática e P12 obtém 33,3 por cento e 0 por cento nas EQ1 e EQ2 de matemática, respectivamente). Os dados de P10 não aparecem porque esse participante não atingiu os critérios mínimos exigidos para essa etapa. Destaca-se que todas as tentativas nas quais o rendimento está abaixo de 80 por cento referem-se às equivalências de matemática. Esses dados sugerem um maior grau de dificuldade no emparelhamento entre estímulos arbitrários que se referem à aquisição do comportamento de identificar números se comparados à aquisição do comportamento de ler e escrever.

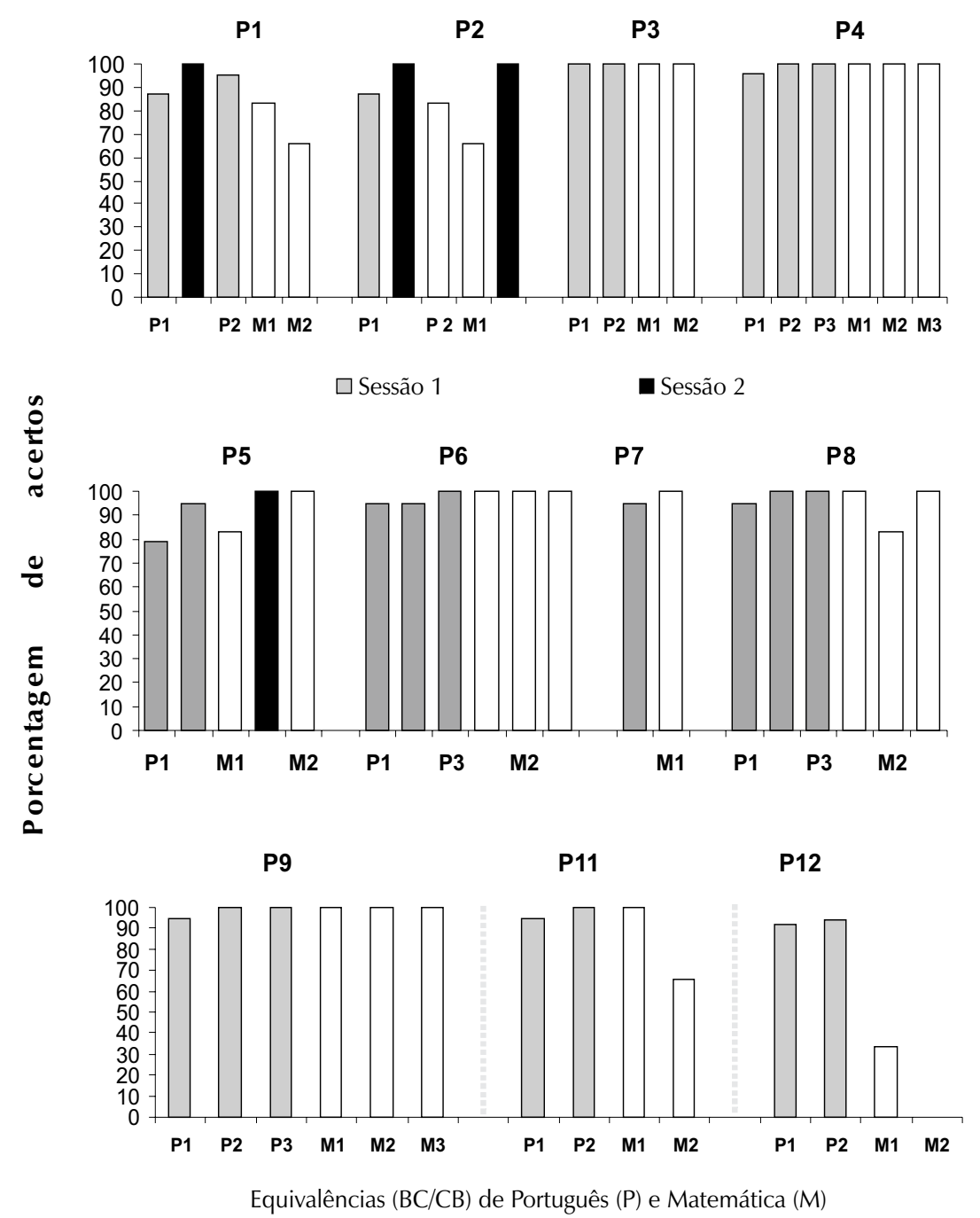

Figura 5. Porcentagem de acertos das relações BC e CB dos testes de equivalência dos participantes $1,2,3,4,5,6,7,8,9,11$ e 12 . 
Os dados relativos à leitura de generalização das palavras ensinadas podem ser vistos na Figura 6 . Todos os Ps leram as novas palavras apresentadas com alto percentual de acertos, com exceção dos Ps 2, 11 e 12, com variabilidade mais acentuada que os demais Ps.

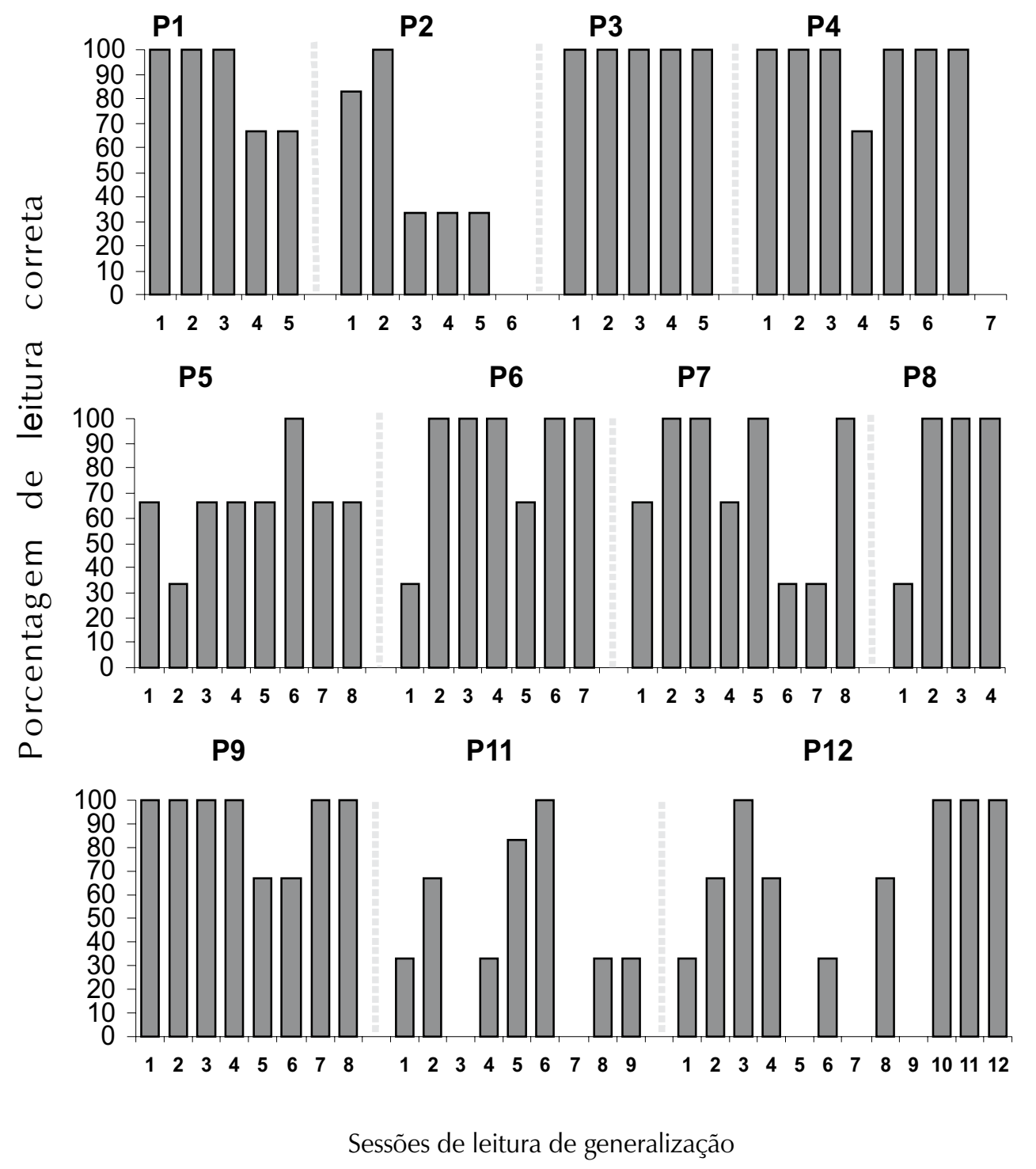

Figura 6. Porcentagem de acertos nas sessões de leitura de palavras novas (rCD) formadas com sílabas das palavras ensinadas.

Na Tabela 3, pode-se visualizar tanto as palavras e números ensinados nas atividades de português e matemática ao longo do procedimento, como as sentenças emergentes apresentadas nos testes de agrupamento.

Observa-se na Tabela 3 a presença de palavras não ensinadas, como uma e duas, no caso dos estímulos serem figuras ( 1 e 2, por exemplo) acompanhadas de palavras do gênero feminino (2 camas, por exemplo), criando a necessidade da criança tornar equivalente ambos os estímulos (um e 1, duas e 2), demonstrando assim, a leitura com compreensão. 
Tabela 3. Etapas do ensino de palavras, de numerais, ordinais e etapa do agrupamento de numerais/ palavras e ordinais/palavras.

\begin{tabular}{|c|c|c|c|c|c|c|}
\hline Português & \multicolumn{3}{|c|}{ Matemática } & \multicolumn{3}{|c|}{ Agrupamento } \\
\hline Etapa & $\begin{array}{l}\text { Palavras } \\
\text { ensinadas }\end{array}$ & $\begin{array}{l}\text { Numerais } \\
\text { ensinados }\end{array}$ & $\begin{array}{l}\text { Ordinais } \\
\text { ensinados }\end{array}$ & \multicolumn{3}{|c|}{ TESTEDEAGRUPAMENTO 1} \\
\hline \multirow[t]{3}{*}{ Linha de base } & cama & 1 & um & \multirow{2}{*}{\multicolumn{2}{|c|}{ Sentenças apresentadas }} & \multirow{2}{*}{$\begin{array}{l}\text { Palavras de } \\
\text { generalização }\end{array}$} \\
\hline & mago & 2 & dois & & & \\
\hline & foca & 3 & três & \multirow[b]{2}{*}{$\begin{array}{l}1 \text { cama } \\
\text { uma cama } \\
2 \text { camas } \\
\text { duas } \\
\text { camas } \\
3 \text { camas } \\
\text { três camas } \\
1 \text { foca } \\
\text { uma foca } \\
2 \text { focas } \\
\text { duas focas } \\
3 \text { focas } \\
\text { três focas } \\
1 \text { boca } \\
\text { uma boca } \\
2 \text { bocas }\end{array}$} & \multirow[b]{2}{*}{$\begin{array}{l}\text { duas bocas } \\
3 \text { bocas } \\
\text { três bocas } \\
1 \text { calo } \\
\text { um calo } \\
2 \text { calos } \\
\text { dois calos } \\
3 \text { calos } \\
\text { três calos } \\
1 \text { lobo } \\
\text { um lobo } \\
2 \text { lobos } \\
\text { dois lobos } \\
3 \text { lobos } \\
\text { três lobos }\end{array}$} & \multirow{2}{*}{$\begin{array}{ll}\text { uma } & \text { duas } \\
\text { camas } & \text { magos } \\
\text { focas } & \text { bocas } \\
\text { calos } & \text { lobos }\end{array}$} \\
\hline Exclusão 1 & $\begin{array}{l}\text { boca } \\
\text { calo } \\
\text { lobo }\end{array}$ & $\begin{array}{l}1 \\
2 \\
3\end{array}$ & $\begin{array}{l}\text { um } \\
\text { dois } \\
\text { três }\end{array}$ & & & \\
\hline
\end{tabular}

TESTEDEAGRUPAMENTO 2

\begin{tabular}{|c|c|c|c|c|c|c|c|}
\hline \multirow[t]{2}{*}{ Exclusão 2} & $\begin{array}{l}\text { bala } \\
\text { lago }\end{array}$ & $\begin{array}{l}4 \\
5\end{array}$ & $\begin{array}{l}\text { quatro } \\
\text { cinco }\end{array}$ & \multicolumn{2}{|c|}{ Sentenças apresentadas } & \multicolumn{2}{|c|}{$\begin{array}{l}\text { Palavras de } \\
\text { generalização }\end{array}$} \\
\hline & gota & 6 & seis & 5 balas & seis lagos & balas & lagos \\
\hline Exclusão 3 & $\begin{array}{l}\text { doce } \\
\text { cela } \\
\text { lata }\end{array}$ & $\begin{array}{l}4 \\
5 \\
6\end{array}$ & $\begin{array}{l}\text { quatro } \\
\text { cinco } \\
\text { seis }\end{array}$ & $\begin{array}{l}\text { quatro gotas } \\
\text { seis doces } \\
\text { quatro balas } \\
\text { seis gotas } \\
5 \text { doces } \\
\text { seis balas } \\
5 \text { gotas } \\
\text { quatro doces }\end{array}$ & $\begin{array}{l}\text { cinco celas } \\
4 \text { latas } \\
\text { cinco lagos } \\
4 \text { celas } \\
6 \text { latas } \\
4 \text { lagos } \\
6 \text { celas } \\
\text { cinco latas }\end{array}$ & $\begin{array}{l}\text { gotas } \\
\text { celas }\end{array}$ & $\begin{array}{l}\text { doces } \\
\text { latas }\end{array}$ \\
\hline
\end{tabular}

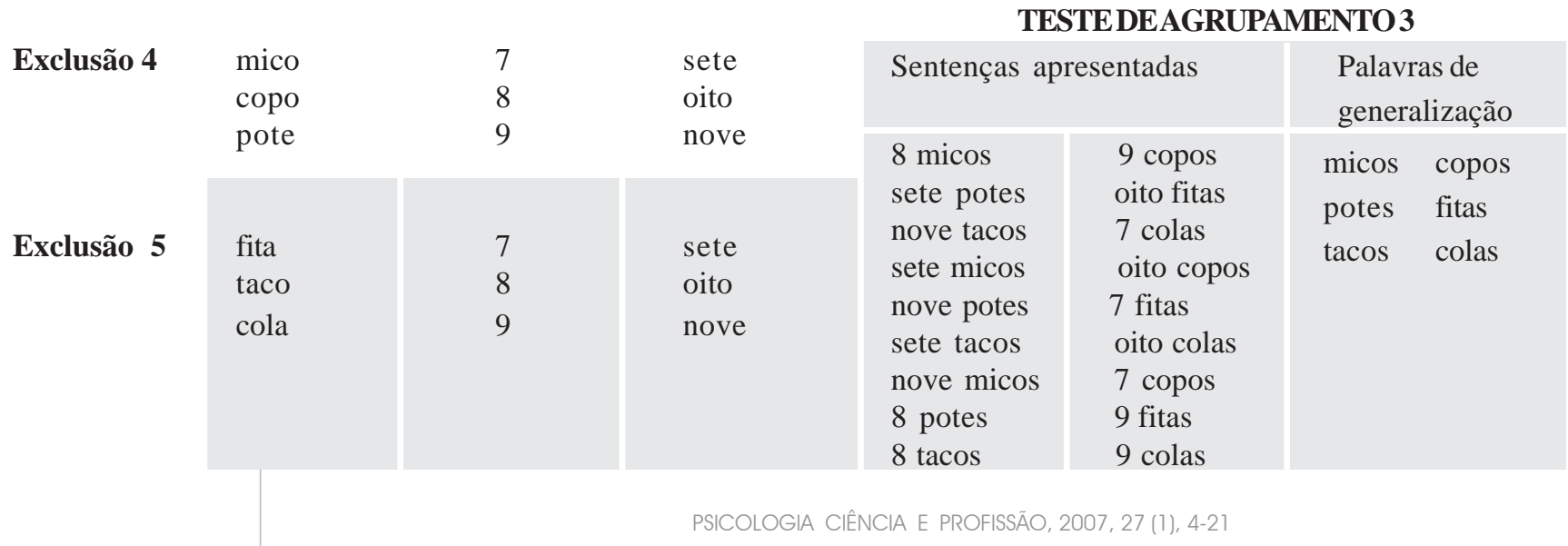


Na composição das palavras de ensino, sílabas semelhantes foram alocadas tanto na primeira, como na segunda posição das diferentes palavras para aumentar o controle discriminativo da leitura, conforme os achados de Hubner e Matos (1997) e d'Oliveira e Matos (1993).

Uma das condições que pode ter aumentado a probabilidade de ler corretamente as palavras de generalização foi a consequenciação positiva da posição das sílabas das palavras de ensino durante a etapa de exclusão destas palavras. No presente procedimento as sílabas foram alocadas em diferentes posições, permitindo a ocorrência de leitura recombinativa. Por exemplo, nas palavras caMA e MAgo, o MA foi reforçado tanto na segunda como na primeira posição e nas palavras CAma e foCA, o CA foi reforçado tanto na primeira como na segunda posição (Matos e cols.,1997). Esse procedimento foi realizado com as palavras de todas as exclusões. A alta porcentagem de leitura correta das palavras de generalização verificada na maioria dos casos pode ser explicada pelo uso dessa estratégia.

De acordo com os resultados dos testes de agrupamento, verifica-se que os comportamentos de ler e escrever, ensinados independentemente do ensino do comportamento de identificar números emergiram como uma nova classe, uma classe conjunta de ler e escrever palavras e identificar números. Dessa forma, os dados corroboram aqueles obtidos por Sidman (1990), de Rose (1993), Mackay (1985) em que, além do ensino de novas relações, relações emergentes ou de generalização também surgiram. As novas relações que surgiram foram não apenas de equivalência (“1” com “um”, “dois” com "2", "três” com “3”, etc.), ou seja, relações intra-classes, mas também relações emergentes ou de generalização, ou seja, inter-classes (“1 mago”, “dois magos”, “3 magos”, etc.).

\section{Conclusão}

Os resultados do teste de agrupamento indicam a emergência conjunta dos comportamentos de ler e escrever palavras e identificar números para todos os Ps. A Figura 7 mostra o desempenho inicial dos Ps. Nessa figura pode ser visto que todos os Ps lêem com 100 por cento de acertos os números apresentados $(1,2,3 \ldots)$, identificam as quantidades $(0,00,000 \ldots)$ com porcentagem de acerto inferior à porcentagem de identificação dos números, contudo não lêem os numerais (um, dois, três ...) com exceção de P9 e não lêem as palavras apresentadas.

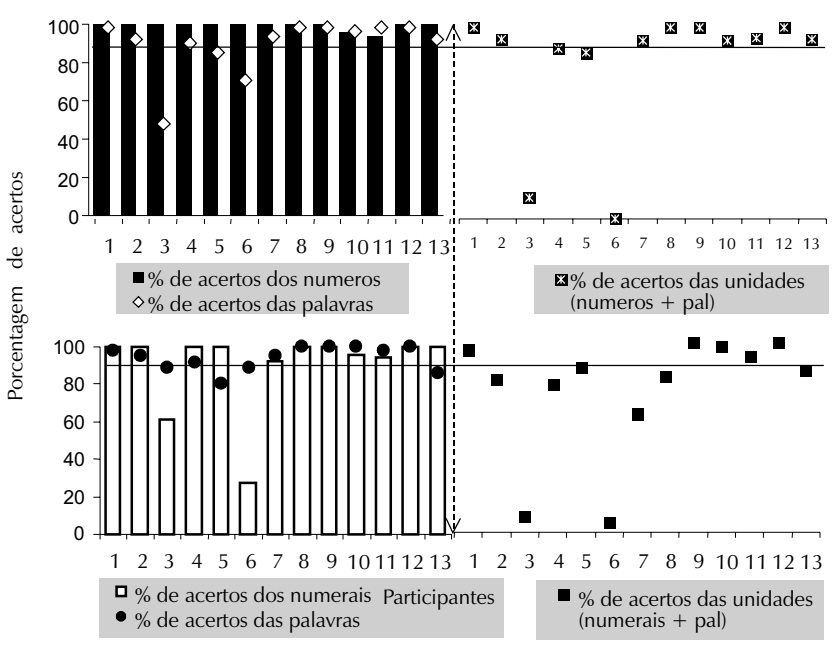

Figura 7. Porcentagens de acertos no teste de agrupamento: identificação de números e leitura de palavras (gráfico superior esquerdo); leitura das unidades completas (números + palavras) 
(gráfico superior direito); identificação de numerais e leitura de palavras (gráfico inferior esquerdo); leitura das unidades completas (numerais + palavras) (gráfico inferior direito).

Nem todos os Ps ficaram sob o controle de estímulos estabelecido. Foi o caso de P10 que permaneceu apenas na exclusão 1 , evidenciando assim que este procedimento não se mostrou eficaz para esse participante, diagnosticado com Transtorno de Déficit de Atenção por Hiperatividade (TDAH). Ressaltase que a criança não deve ser entendida como incapaz para aprender tais repertórios e que uma possível explicação pode estar na possibilidade de os recursos utilizados no procedimento não terem atendido as especificidades do participante.

Os dados obtidos indicam que o procedimento foi eficiente para instalar os repertórios de leitura de palavras inteiras (mago, lobo, cama, etc.), identificação de números (um, 1, dois, duas, três, etc.), bem como a leitura generalizada de números e palavras juntos (p.ex. um mago, dois lobos, três camas, etc.). Os dados permitem identificar que, ao se ensinar independentemente o ler e o escrever palavras e o identificar números, na situação de teste de agrupamento em que as configurações foram apresentadas juntas, emergiram, além das relações BC e CB, também a relações CD. Observa-se, portanto, que os Ps, após terem sido ensinados a responder às configurações de som/números/ nomes separadamente das configurações som/ palavras/figuras, passaram a responder ao agrupamento dessas configurações. Ou seja, de um padrão de generalização intra-classes (números / e seus respectivos nomes e palavras ensinadas / e palavras de generalização) para um padrão inter-classes, isto é, números/nomes juntamente com palavras (relações C’D). Um aspecto interessante a ser registrado foi o padrão comportamental emergente dessa nova configuração. Aproximadamente metade dos Ps ficam sob controle imediato das novas configurações, ou seja, respondem com porcentagens altas (em torno de 80 por cento) e a outra metade apresenta um padrão característico de um processo de aquisição, isto é, com baixas porcentagens iniciais e aumento progressivo dessas porcentagens na medida em que o procedimento se desenrolava.

E como explicar os dados do teste de agrupamento em que aproximadamente metade dos Ps (1, 2, 5, 6 e 12) apresenta um processo de aquisição gradual das relações número/palavra enquanto que a outra metade dos Ps $(3,4,7,8,9$ e 11) responde às configurações número/palavra com porcentagens altas de acerto logo nas primeiras sessões?

Os resultados obtidos indicam a relevância do procedimento em âmbito escolar, uma vez que possibilitou o aumento do repertório de leitura e identificação de números de crianças que apresentavam um repertório significativamente menor dos comportamentos de ler e escrever palavras e identificar números em relação ao restante da classe escolar. É possível que os resultados tenham influenciado também a auto-estima dos Ps, pois nenhum deles foi reprovado no ano letivo da realização da pesquisa. Ademais, a psicologia pode contribuir significativamente para a educação no estudo de novas formas de aprender por meio de recursos tecnológicos de informação, contribuindo para a ressignificação do espaço escolar, com a utilização de um instrumento individual e computadorizado que pode auxiliar o trabalho docente, servindo como um recurso extra no processo de ensinoaprendizagem. 
José Gonçalves Medeiros
Laboratório de Linguagem e Comportamento Verbal (LAB-LIN) -

Universidade Federal de Santa Catarina(UFSC)

Caixa Postal 5060

Fax: (048) 3331-9984 Fone: (048) 9972-4042CEP: 88040-970 - Florianópolis, SC.

E-mail: rubimedeiros@yahoo.com.br

Aline Vettorazi

Laboratório de Linguagem e Comportamento Verbal (LAB-LIN) - Departamento de Psicologia. Universidade Federal de Santa Catarina (UFSC), Florianópolis, SC.

E-mail:Alinevttzz@hotmail.com

Amanda Kliemann

Laboratório de Linguagem e Comportamento Verbal (LAB-LIN) - Departamento de Psicologia. Universidade Federal de Santa Catarina (UFSC), Florianópolis, SC. E-mail:amanda_kliemann@yahoo.com.br

Layla Kurban

Laboratório de Linguagem e Comportamento Verbal (LAB-LIN) - Departamento de Psicologia. Universidade Federal de Santa Catarina (UFSC), Florianópolis, SC. E-mail:laylakurban@hotmail.com

Maria Salete Mateus

Laboratório de Linguagem e Comportamento Verbal (LAB-LIN) - Departamento de Psicologia. Universidade Federal de Santa Catarina (UFSC), Florianópolis, SC. E-mail:mariasaletematheus@yahoo.com.br

AIELLO, A. L. R. Efeitos de um procedimento de resposta construída sobre a rede de relações de equivalência envolvida em leitura e escrita em crianças com história de fracasso escolar. 1995. Tese (Doutorado em Psicologia) - Universidade de São Paulo, São Paulo.

BARROS, R. S. Análise do comportamento: da contingência de reforço à equivalência de estímulos. Caderno de Textos de Psicologia, Ribeirão Preto (SP), v. 1, n.1, p. 7-14, 1996.

D’OLIVEIRA, M. H. \& Matos, M. A. Controle discriminativo na aquisição da leitura: Efeito da repetição e variação na posição das sílabas e letras. Temas em Psicologia, Ribeirão Preto (SP), n. 2, p. 99-108, 1993.

D’OLIVEIRA, M. H. Estudos em relações de equivalência: uma contribuição à identificação da leitura sob controle de unidades mínimas na aprendizagem de leitura com pré-escolares. 1990. Tese (Doutorado em Psicologia) - Universidade de São Paulo, São Paulo.

DE ROSE, J. C. C. Classes de estímulos: implicações para uma análise comportamental da cognição. Psicologia: Teoria e Pesquisa, Brasília, v. 9, n. 2, p. 283-303, 1993.

DIXON, L. S. The nature of control by spoken words over visual stimulus selection. Journal of the Experimental Analysis of Behavior, n. 27, p. 433-442, 1977.

GOYOS, C., e ALMEIDA, J. C. Mestre (Version 1.0) [Computer Software]. São Carlos, Brazil: Mestre Software, 1996.

HÜBNER, M. M. O paradigma de equivalência e suas implicações para a compreensão e emergência de repertórios complexos. Em R. A. Banaco (Org.), Sobre comportamento e cognição: aspectos teóricos, metodológicos e de formação em análise do comportamento e terapia cognitivista (p. 423-430). São Paulo: ARBytes, 1997.

MACKAY, H. A. Stimulus equivalence in rudimentary reading and spelling. Analysis and Intervention in Developmental Disabilities, n. 5, p. 373-387, 1985.

MATOS, M. A., HÜBNER, M. M. \& PERES, W. Leitura generalizada: procedimentos e resultados. Em R. A. Banaco (Org.), Sobre comportamento e cognição: aspectos teóricos, metodológicos e de formação em análise do comportamento e terapia cognitivista (p. 471). São Paulo: ARBytes Editora Ltda, 1997.
MEDEIROS, J. G, KONESCKI, G. E. e SOUZA,A. P.(1993). Alternativa de alfabetização para crianças com dificuldades de aprendizagem em leitura e escrita. Trabalho apresentado no Seminário Catarinense de Iniciação Científica, Florianópolis, MEDEIROS, J. G., MONTEIRO,

G. \& SILVA, K. Z. O ensino da leitura e escrita a um participante adulto. Temas em Psicologia, Ribeirão Preto (SP), n. 1, p. 65-78, 1997.

MEDEIROS,J.G;ANTONAKOPOULU,A.;AMORIM,K. \& RIGHETTO, A. C. O uso da discriminação condicional no ensino da leitura e escrita. Temas em Psicologia, Ribeirão Preto (SP), n. 1, p. 23-32, 1997.

MEDEIROS, J.G., TEIXEIRA., C.M. , CABRAL, C., SILVA, A. B. C. E BRANDÃO, L. $O$ ensino de novas palavras a crianças com desempenho acadêmico insuficiente através do procedimento de exclusão. Brasília, DF: CNPq, 1996. (Relatório de projeto de pesquisa)

MELCHIORI, L. E., SOUZA, D. G. \& DE ROSE, J. C. C. Aprendizagem de leitura por meio de um procedimento de discriminação sem erros (exclusão): uma replicação com pré-escolares. Psicologia: Teoria e Pesquisa, Brasília, v. 8 n.1, p. 101-111, 1992.

MONTEIRO, G.; MEDEIROS, J.G. A contagem oral como pré-requisito para a aquisição do conceito de número com crianças pré-escolares. Estudos de Psicologia, Natal, v. 7, n.1, p. 73-90, 2002.

SIDMAN, M. \& CRESSON, O. Reading and crossmodal transfer of stimulus equivalencies in severe mental retardation. American Journal of Mental Deficiency, n. 77, p. 515-523, 1973.

SIDMAN, M. \& TAILBY, W. Conditional discrimination vs. matchingto-sample: an expansion of the testing paradigm. Journal of the Experimental Analysis of Behavior, n. 37, p. 5-22, 1982.

SIDMAN, M. Reading and auditory-visual equivalencies. Journal of Speech and Hearing Research, n. 14, p. 5-13, 1971.

SIDMAN, M. Equivalence relations: where do they come from? In D.E. Blackman \& H. Lejeune (Eds.), Behaviour analysis in theory and practice: contributions and controversies. Brighton, U.K.: Erlbaum, 1990.

SOUZA, D. G. \& DE ROSE, J. C. Transferência de controle de estímulos de figuras para texto no desenvolvimento de leitura generalizada. Temas em Psicologia, Ribeirão Preto (SP), n. 1, p. 33-46, 1997.

\section{Referências}

